\begin{tabular}{|c|c|c|c|}
\hline & $\begin{array}{r}\text { D } \\
\text { Anna } \\
\text { http://wv }\end{array}$ & $\begin{array}{l}\text { J.2.1 } \\
\text { Journal } \\
\text { s/index.php }\end{array}$ & 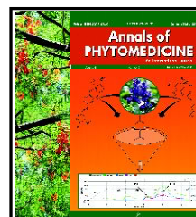 \\
\hline & Print ISSN : 2278-9839 & Online ISSN : 2393-9885 & 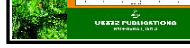 \\
\hline
\end{tabular}

Invited commentary

\title{
Some customary edible plants of incredible medicinal worth
}

\author{
Nazim Sekeroglu \\ Department of Horticulture, Faculty of Agriculture, Killis 7 Aralik University, Killis 79000, Turkey
}

Received September 15, 2019: Revised November 5, 2019: Accepted November 7, 2019: Published online December 30 , 2019

Even though, the contemporary medical technology made a tremendous progress, yet facing a huge challenge with respect to its easy availability to the needy people worldwide. In many developing and under-developed nations, the scarcity of effective modern medication is still a great lacuna in the healthcare system and policies. In these nations, the limited supply of advanced medicines is due to lack of transportation and high cost. Consequently, in such nations, a large proportion of the population has to depend on their traditional or complementary systems of medicine for general healthcare (Hegde, 2003).

In the current scenario, health problems have greatly risen due to unhealthy lifestyles and ignorance towards the environmental pollution. The ever increasing environmental toxicity has induced many stress related changes in humans and pathogens both. As a result, the immunity of human beings has decreased to an alarming level while the adaptation/resistance in pathogens, showed a reverse effect. Thus, complications have arisen further due to multidrug resistance in pathogens. The other major problem is related to the negative side effects of allopathic or synthetic chemical drugs on the vital organs of the diseased persons.

Thus, to provide effective and safe healthcare with better physiological compatibility, at an effective cost and fewer/no adverse effects, the research focus is again shifting towards the conventional systems of medicine and the area of phytomedicine is now an emerging as a thrust area of healthcare (Ansari et al., 2019). The year 2013 with the launch of 'WHO Traditional Medicine Strategy 2014-2023' marks a significant development in this arena, globally. This strategically motivated planning emphasized on the promotion of earliest medicinal knowledge, which is effective, safe, almost free of charges and has wide acceptance.

India is believed to be one of the oldest centers for medicinal plant research with evidences indicating that in ancient India, Shusruta and Charaka were the well known medicine men with exceptional knowledge of surgical acts also. They have written 'Sushruta, Samhita' and 'Charaka Samhita', respectively, the manuscripts

Author for correspondence: Dr. Nazim Sekeroglu Professor, Department of Horticulture, Faculty of Agriculture, Killis 7 Aralik University, Killis 79000, Turkey

E-mail: nsekeroglu@gmail.com

Tel.: +90-5324015512; +90-3488142667; Fax: +90-3488142669

Copyright@2019 Ukaaz Publications. All rights reserved.

Email: ukaaz@yahoo.com; Website: www.ukaazpublications.com related to alternative medicine and surgery. Both of these are considered as the systematic writings having a precious classic text on medicinal practices. Archeological excavations have gathered numerous evidences suggestive of the utilization of plants as medicine. However, since the beginning of $19^{\text {th }}$ century, the mode of treatment was drifted towards the use of allopathic medicines in the India, even today, majority of the modern populace prefer allopathic medicines for treatment. But, the rural population of India even today depends on the ancient Indian medicinal practices like ayurveda, unnani and siddha.

Now, the urban population has also realized the side effects of allopathic medicines and started to prefer herbal drugs or phytomedicine or phytotherapy for maintenance of health as well as therapy of various ailments (Pandey et al., 2013; Mafuva et al., 2014). These practices are all based on the use of plants/plant parts, viz., roots, bark, leaves, flowers, fruits, seeds and even the whole plants (Falodun, 2010).

As a result, the Indian government established a department of AYUSH to promote plant bases medication. The canopy of AYUSH covers herbs, plant parts or preparations, involving active ingredients of plant origin (AYUSH, 2012). In India, it is believed that approximately 25,000 plant-based formulations are consumed for their medicinal properties (Joy et al., 2004). For over 28, chronic diseases, herbal formulae are utilized as they provide therapeutic relief (Sharma et al., 2007).

The secondary metabolites in plants termed phytochemicals are largely responsible for their medicinal properties. These active ingredients classified on the basis of their chemical composition include alkaloids, saponins, terpenoids, flavonoids, sterols, volatile oils, phenols and biomolecules such as sugars and proteins. Various herbs and spices hold great potential for their medicinal properties. Few of them along with their novel medicinal importance have been discussed below:

1. Aegle marmelos (L.) Corrêa (Bael), a member of family Rutaceae is routinely used for relief from dysentery and diarrhoea, peptic ulcers, and as a laxative (Baliga et al., 2011). The fruit juice treats gastric problems, if consumed empty stomach and the paste of the leaves helps during malaria in relieving high fever (Debbarma et al., 2017). A decoction of fresh leaves can treat cough and can relieve eye problems (Jeyaprakash et al., 2011). It is rich in (3,3-dimethylallyl) halfordinol (anti-diabetogenic 
and lipolytic activities), Limonene (anti-glycative properties), aegelin and lupeol (antihyperglycemic) (Gandhi et al., 2012; Saravanan et al., 2014)

2. Coriandrum sativum L. (Dhaniya), belonging to the family Apiaceae, has been used for its hepatoprotective, hypoglycemic and for its hypolipidemic activities with improved antioxidant potential. The spice has been used for its medicinal properties due to the presence of terpenes (Johanna, 2003) and caffeic, chlorogenic, ferulic and gallic acids (Bajpai et al., 2005). Powdered fruit when administered to cholesterol-fed rats lead to decreased plasma LDL-cholesterol, total cholesterol levels, as well as total lipid concentrations, though it leads to increase in the HDLcholesterol (Suliman et al., 2008).

3. Zingiber officinale Rosc. (Ginger), belongs to the family Zingiberaceae, this rhizome has multiple health benefits. It is consumed for treatment of disorders such as diabetes and hypertension, relief from neuromuscular ailments as arthritis, sprain, muscular aches, cramps and infectious diseases like sore throats, and fever (Haniadka et al., 2013). Its constituents provide specific properties as an antioxidant, antidiabetic, hypocholesterolemic and hypolipidemic potential (Rani et al., 2012). The anti-inflammatory properties can be accounted for structurally related compounds as gingerols, shogaols and paradols (Grzanna et al., (2005). Ghayur and Gilani (2005) and Ali et al. (2008) suggested that ginger can lower blood pressure as it stimulates muscarinic receptors and blocks calcium channels.

4. Cuminum cyminum L. (Jeera) belongs to the family Apiaceae. It has wide usage for treatment of dyspepsia, diarrhoea and jaundice and an aqueous extract showed potential to lower blood glucose in alloxan-induced diabetic rats, along with the reduction in plasma and tissue lipid concentrations (Lee, 2005). Saraswat et al. (2009) reported the prevention of non-enzymatic glycation of proteins, with the potential to alleviate diabetic complications. In diabetic animals, alterations in metabolic levels, such as lowering of blood urea and reduced excretions of urea and creatinine were noted by Villatgamuwa et al. (1998). Cumin is useful as a chemopreventive agent as a cumin seed-mixed diet significantly, inhibited the stomach tumor burden induced by benzo(a)pyrene [B(a)P] (Gagandeep et al., 2003). The active ingredient include cuminaldehyde (Sowbhagya, 2013), alongwith cuminal, cuminic alcohol, safranal, $p$-cymene, $\beta$-pinene, $\gamma$-terpinene and volatile oils (Chatterjee and Prakash, 1997).

5. Murraya koenigii (L.) Spreng (Curry) belongs to to Family Rutaceae. The leaves (kadipatta) contain several carbazole alkaloids as mahanimbine, mahanine, mahanimbicine, euchrestine $\mathrm{B}$ and bismurrayafoline, have been traditionally used for its antioxidant properties. Ningappa and Srinivas (2008) isolated a $35 \mathrm{kDa}$ antioxidant protein PII, having potential to inhibit lipoxygenase activity and lipid peroxidation on erythrocyte ghosts and ROS scavenging activity. In diabetic ob/ob mice, Xie (2006) depicted a decrease in blood glucose and cholesterol levels along with a reduction in body weight on leaf supplementation. Potential to lower blood glucose levels in streptozotocin-induced moderately and alloxan- induced mild diabetic rats, fed with curry leaf powder showed a decrease of $8.2 \%$ and $21.4 \%$, respectively, Yadav (2002). Khan et al. (1996) reported in high fat-fed young male albino rats, reduction in total serum LDL, VLDL and cholesterol concentrations and release of lipoproteins into the circulation. Also, an increase in HDL concentration, and lecithin cholesterol acyltransferase (LCAT) activity were observed on supplementation.

6. Cinnamomum verum J. Presl. (Dalchini), belongs to Lauraceae family. The pharmacological properties of this plant include antioxidant, antidiabetic, antibacterial, astringent antinociceptive, digestive, hypolipidemic and stimulant (Lopez et al., 2005; Shan et al., 2005). Wahab et al. (2009) reported that the major constituents comprising $>95 \%$ of the cinnamon oil, are, namely; cinnamaldehyde (77.1\%), (E)- $\beta$-caryophyllene $(6.0 \%)$, $\alpha$-terpineol (4.4\%), and eugenol (3.0\%). In spontaneously hypertensive rats, cinnamon prevents sucrose induced increase in blood pressure (Preuss, 2006) while in cholesterol-fed rats, hepatic HMGCoA reductase activity is inhibited along with a suppression in lipid peroxidation in the liver (Kannappan, 2005). Solomon and Blannin (2009) fed $5-20 \mathrm{mg} / \mathrm{kg} /$ day cinnamaldehyde to streptozotocininduced diabetic rats and found a decrease in plasma glucose, glycosylated haemoglobin, cholesterol and triglyceride concentrations, with an increase observed in plasma insulin, HDLcholesterol concentrations and hepatic glycogen. Use of cinnamon as hypolipidemic is well-known and in rats fed with cholesterol and cinnamate $(0.1 \mathrm{~g} / 100 \mathrm{~g})$, inhibition of hepatic HMGCoA reductase activity and lipid peroxidation in the liver is noted.

7. Curcuma longa L. (Haldi) belongs to the family Zingiberaceae. This plant is well known for medicinal uses of its rhizomes as antiarthritic, anticancer, antibacterial, anti-hepatotoxic, antifungal, anti-inflammatory, antihistaminic, hypocholesterolemic. It is also known to improve Alzheimer's, asthma, blood impurities, cough, diabetes, obesity and worm manifestation (Chatterjee and Pakrashi, 1997). Curcumin along with essential oils such as $p$ cymene-8-ol in flower $(26 \%)$ and phellandrene $(33 \%)$ in leaf are the major phytochemicals (Leela et al., 2002). Many properties of curcumin are attributed to its role in mediating the regulation through cytokines, growth factors, protein kinases, transcription factors and other enzymes. (Agarwal, 2007). The antiinflammatory properties of haldi are attributed to its inhibitory effects on lipoxygenase (LOX) and cyclooxygenase-2 (COX-2), along with inducible nitric oxide synthase (iNOS). Further, improper up-regulation of above enzymes is coupled to the pathophysiology of cancer as well. As a result, the spice is now also consumed for its chemopreventive effects (Menon and Sudheer, 2007). Jagetia and Aggarwal (2007), highlighted the immunomodulatory activities of curcumin by modulating the activation of $\mathrm{T}$ cells, B cells, macrophages, neutrophils, natural killer cells, and dendritic cells; downregulating the expression of proinflammatory cytokines as chemokines, IL-1, IL-2, IL-6, IL8, IL-12 and TNF, via transcription factor NF-kappaB inactivation., Weisberg et al. (2008) evaluated the effects of curcumin on obesity associated with diabetes, in high-fat fed obese and leptin-deficient $o b / o b$ mice, and suggested that it possibly also alters fatty acid metabolism. Interestingly, curcumin has been found to exhibit therapeutic potential in both types of 
diabetes, as in streptozotocin- induced diabetic rats. However, it did not show any hypoglycaemic activity (Srinivasan, 2005).

8. Trigonella foenum-graecum L. (Methi) belongs to the family Fabaceae. This herb has been used for curing abdominal pain, anorexia, body ache, diabetes and deficient lactation. These effects are mediated via its active chemical constituents, as saponins ( $\beta$ sitosterol), flavonoids, alkaloids (trigonalin, vitexin, and tigogenine), galactomannan and volatile oils. It possesses antiinflammatory, antitumour, antipyretic, analgesic, hypoglycaemic, hypolipidemic and pharmacological properties (Chatterjee and Prakash, 2005). Meghwal and Goswami (2012) suggested that seeds of methi contain $65 \%$ fibre which reduces energy intake, increasing satiety and controlling blood sugar. The fiber also has the potential to bind and remove toxins from the intestine, thus helping in prevention of cancer. Fenugreek contains phenolic and flavonoid compounds which help to enhance its antioxidant capacity (Balch et al., 2003) which holds benefit for liver and pancreas function and these properties are enriched in germinating seeds due to better bioavailability. Kaviarasan et al. (2007) exhibited the potential of hydroxyl radicals scavenging and hydrogen peroxide-induced LPO inhibition in mitochondria as the extract is rich in antioxidants and cellular structures are protected from oxidative damage. The hypocholesterolaemic property is evident from the ability of an alcoholic extract to inhibit deoxycholate and taurocholate absorption in a dosedependent manner when reductions ranging from 18 to $26 \%$ in plasma cholesterol levels were observed (Gupta, 2010)

9. Allium sativum L. (Garlic/Lahsun), a member of family Amaryllidaceae is globally used with a broad range of therapeutic responses like, lowering blood pressure, glucose levels, lipid levels and flatulence; reducing atherosclerosis risk and obesity; and is well known as antimicrobial, anticancer and hepatoprotective agent. These effects of garlic have been credited to the presence of sulphur compounds of which Allicin (diallyl thiosulphinate) is the major bioactive component and allyl methyl thiosulphonate, 1 -propenyl allyl thiosulphonate and $\gamma$-L-glutamyl-S-allyl-Lcysteine being other constituents (Banerjee et al., 2003). Studies have shown that garlic has the ability to inhibit angiotensin II through inhibition of angiotensin converting enzyme thus promoting vasodilation (Benavides et al., 2007). Animal studies, depict organ-protective effects on the heart, liver and kidneys helping in control of blood pressure in hypertensive patients as it inhibits thickening of lipid-filled lesions on plaques produced post-injury to right carotid artery in cholesterol-fed rabbits. Area of thoracic aorta covered by fatty streaks is also reduced by the spice (Reinhart et al., 2008; Ried et al., 2009).

The above mentioned herbs/spices have been used in the household regularly so their consumption as medicines forms a psychological barrier. However, the same if dissolved will help in providing health benefits with few adverse effects at a low cost. With respect to herbal products, another area gaining popularity is nutritional supplements and functional foods. They provide nutrients which go amiss in the diet or its adequate quantity is not consumed through the diet. They are rich in antioxidants, minerals, macronutrients, vitamins, etc., all of which promote good health. This concept was prevalent since ancient times in India as formulations like chyawanprash, musli pak, and ashwagandhadi lehyam were consumed for maintenance of good health. The different phytochemicals in herbal medicines work singly, in additive fashion or even synergistically, insight to which is essential for developing novel products. This holistic approach to treatment is a key factor for the success of Indian traditional medicine, especially Ayurveda, around the world (Sheth, 2005).

A bio-enhancer from pipali 'Piperine', and so also 'Vijayasar" (aqueous decoction of Ptero-carpus marsupium Roxb.) have been successfully evaluated in clinical studies as hypoglycemic and antidiabetic drugs. A US patent has been approved for an herbal anti-psoriatic medicine containing Argemone mexicana (L.). The Central Drug Research Institute (CDRI) marketed a drug from Commiphora wightii (gugulipid fraction) for relief from hyperlipidemia and atherosclerosis while Regional Research Laboratories (Jammu) has commercialized Boswellia serrata Roxb., gum resin as a non-steroidal anti-inflammatory drug, exhibiting hypolipidemic effect (Gurib-Fakim, 2011; Sen and Chakraborty, 2015). In Asian and European countries, Brahmi (Bacopa monnieri L.) product developed by the CSIR and CDRI is marketed.

Major challenges faced in acceptance of herbal products are lack of standard protocols for drug standardization, quality control, and assurance (Rana and Rana, 2014). The heavy metal contamination beyond permissible limit and adulteration and substitution of undeclared components, added for better efficacy, is a concern for acceptance of herbal products in a study of 260 patented medicines. About $20 \%$ drugs available online have been found to be contaminated with heavy metals as lead, mercury, and arsenic, which is another deterrent to online purchase of herb al formulations (Moshi, 2005). GMP application is vital for the quality of the herbal medicines. Further, in our country, most non-conventional medicinal products are made available over the counter (OTC) and strict quality parameters are not adhered to. This arises largely due to the unavailability of conventional quality control and assurance parameters being unavailable due to the complex composition of herbal medicines.

The future of herbal products is bright, but legislations for marketing of herbal products have to be redefined. The need of the hour is to develop standard procedures with recommendations for even cultivation as well as postharvest processing. The research for herbal products should culminate at patenting post which stringent procedures to be monitored during manufacture and marketing strategy. The involvement of local medicine men is an important aspect for a successful program. An ideal solution could be creation of government-certified raw material supply centers across the country, so that verified raw materials are made available. Use of taxonomic, chemical, genomic, and proteomic markers, to ascertain the identity of components can help resolve issues of addition and substitution. With advancement in recombinant DNA technology (RDT) fingerprinting of raw material, if conducted will increase the acceptability of the drugs across the world. (Bandaranayake, 2003; Fan et al., 2006; Saxena et al., 2007; Li, 2008).

In conclusion, it is evident that the demand for novel and well known herbal products will be on the rise due to their safety claims. 
For best availability and promotion of these herbal medicines the role of government policy makers becomes crucial and organization like AAYUSH have to settle all the concerns related to the development and marketing of these products in a well regulated mode. Capacity building in the area of ethnobotany will be a crucial step in this direction because the tribes across the globe are reservoirs of precious information regarding medicinal uses of various plants. Further, submissions for product research and marketing should be evidence-based to increase acceptance to spread the phytomedicine to global markets. Since India is among the mega diversity centers, hence considered as a treasure of phytomedicine with never ending scope. Finally, a coordinated and serious effort of local people, ethnobotanist, herbalists and government officials can do wonders in this area with huge opportunity of employment.

In the proper dissipations of emerging new scientific knowledge, scientific journals play key roles by publishing properly scrutinized and reviewed good quality research articles. It is heartening to note that, currently, important journals are indexed and the journal contents are rapidly made available online to the world. In today's competitive world, the success of a journal depends on, to a large extent, getting good quality research findings including scientific concepts in the form of well-presented manuscripts as well as availing the services of efficient, experienced and unbiased reviewers. In the emerging scenario of the 21 st century, phytomedicine is gaining wider acceptance and importance, because it is truly a multidisciplinary areas, encompassing serveral disciplines. In view of the ever increasing amount of awesome research work to be carried out in the development of phytomedicines and conventional medicines from plants, a matching increase in the number of good quality, reputed journals is a requirement (Pushpangadan, 2013; Subramoniam, 2014). In this context, Annals of Phytomedicine: An International Journal, with a commitment to excellence in publishing cutting edge research in all areas of phytomedicine is a welcome arrival. It is gratifying to see that "Annals of Phytomedicine" is catering to the needs of scientists from different closely related disciplines by promoting the publications on plant medicines and specially by inviting the commentaries of stake holders. It is a challenging and a difficult job to run such a journal successfully. I am very happy and informing you all, working in the field of phytomedicine that "Annals of Phytomedicine: An International Journal" is on its way towards accomplishing its mission and bringing it to the greater heights.

\section{Conflict of interest}

The author declared that there is no conflicts of interest in the course of conducting the research. The author has final decision regarding the manuscript and decision to submit the findings for publication.

\section{References}

Ali, B.H.; Blunden, G.; Tanira, M.O. and Nemmar, A. (2008). Definition, diagnosis and classification of diabetes mellitus and its complications. Part 1: Diagnosis and classification of diabetes mellitus provisional report of a WHO consultation. Food Chem. Toxicol., 46:409-420.

Ansari, M.H.R. and Ahmad, S. (2019). Herbs that heal: Natural remedies for health promotion and longevity. Ann. Phytomed., 8(1):7-18.

Bajpai, M.; Mishra, A. and Prakash, D. (2005). Antioxidant and free radical scavenging activities of some leafy vegetables. Int. J. Food Sci. Nutr., 56:473-481.
Baliga, M.S.; Bhat, H.P.; Joseph, N. and Fazal, F. (2011). Phytochemistry and medicinal uses of the bael fruit (Aegle marmelos Correa): A concise review. Food Res. Int., 44(7)1768-1775.

Bandaranayake, W.M. (2003). Quality control, screening, toxicity, and regulation of herbal drugs. In: Ahmad I, Aqil F, Owais M, eds. Modern phytomedicine-turning medicinal plants into drugs. Weinheim, Germany: Wiley-VCH Verlag. Vedic Books. pp:25-57.

Chatterjee, A. and Pakrashi, S.C. (1997). Treatise on Indian Medicinal Plants. Ayurveda, Vol. pp:1-5.

Debbarma M.; Pala, N.A.; Kumar, M. and Bussmann, R.W. (2017). Traditional knowledge of medicinal plants in tribes of Tripura in northeast. Af. J. Trad. Comp. Med., 14(4):156-168.

Falodun, A. (2010). Herbal medicine in Africa-distribution, standardization and prospects. Res. J. Phytochem., 4(3):154-161.

Fan, X.; Cheng, Y.; Ye, Z. et al. (2006). Multiple chromatographic fingerprinting and its application to the quality control of herbal medicines. Anal. Chim. Acta., 555:217-224.

Gagandeep, S.; Dhanalakshmi, E.; Mendiz, A.; Rao, R.; Kale, R.K. (2003). Chemopreventive effects of Cuminum cyminum in chemically induced forestomach and uterine cervix tumors in murine model systems. Nutrition and Cancer, 47(2):171-180.

Gandhi, G.R.; Ignacimuthu, S. and Paulraj, M.G. (2012). Hypoglycemic and $\beta$-cells regenerative effects of Aegle marmelos (L.) Corr. Bark extract in streptozotocin-induced diabetic rats. Food Chem. Toxicol., 50:1667-1674.

Ghayur, M.N. and Gilani, A.H. (2005). Ginger lowers blood pressure through blockade of voltage-dependent calcium channels. J. Cardiovasc. Pharmacol., 45:74-80.

Grzanna, R.; Lindmark, L. and Frondoza, C.G. (2005). Ginger-an herbal medicinal product with broad anti-inflammatory actions. J. Med. Food., 8:125-132.

Gurib-Fakim, A. (2011). Traditional roles and future prospects for medicinal plants in health care. Asian Biotechnology and Development Review, 13(3):77-83.

Haniadka. R.; Saldanha, E.; Sunita, V; Palatty, P.L.; Fayad, R. and Baliga, M.S. (2013). A review of the gastroprotective effects of ginger (Zingiber officinale Roscoe). Food Funct., 4(6):845-855.

Hegde, B.M. (2003). Future medicare system. J. Indian Acad. Clin. Med., 4:92-95.

Jeyaprakash, K.; Ayyanar, M.; Geetha, K.N. and Sekar, T. (2011). Traditional uses of medicinal plants among the tribal people in Theni District (Western Ghats), Southern India. Asian Pac. J. Trop. Biomed., 1:S20-S25.

Johanna, W. L. (2003). Spicing up a vegetarian diet: chemopreventive effects of phytochemicals. Amer. J. Clin. Nutr., 78(3).

Joy, P.P.; Thomas, J.; Mathew, S. and Skaria, B.P. (2004). Medicinal plants. 2013, and Wakdikar S. Global health care challenge: Indian experiences and new prescriptions. Elec. J. Biotech., 7(3):214-220.

Kannappan, S.; Jayaraman, T.; Rajasekar, P.; Ravichandran, M.K. and Anuradha, C.V. (2006). Cinnamon bark extract improves glucose metabolism and lipid profile in the fructose-fed rat. Singapore Med. J., 47:858-863.

Khan, B.A.; Abraham, A. and Leelamma, S. (1996). Biochemical response in rats to the addition of curry leaf (Murraya koenigii) and mustard seeds (Brassica juncea) to the diet. Plant Foods Hum. Nutr., 49: 295-299.

Lee, H. (2005). Cuminaldehyde: Aldose reductase and $\alpha$-glucosidase inhibitor derived from Cuminum cyminum L. seeds. J. Agric. Food Chem., 53:2446-2450. 
Lopez, P.; Sanchez, C.; Battle, R. and Nerin, C. (2005). Solid- and vapor-phase antimicrobial activities of six essential oils: Susceptibility of selected foodborne bacterial and fungal strains. J. Agric. Food Chem., 53:69396946.

Mafuva, C. and Marima-Matarira, H.T. (2014). Towards professionalization of traditional medicine in Zimbabwe: A comparative analysis to the South African policy on traditional medicine and the Indian Ayurvedic system. Int. J. Herb. Med., 2:154-161.

Moshi, M.J. (2005). Current and future prospects of integrating traditional and alternative medicine in the management of diseases in Tanzania. Tanzan Health Res. Bull., 7:159-167.

National Centre for Biological Sciences (2015). Overview of Indian Healing Traditions. https://www.ncbs.res.in/HistoryScienceSociety/content/ overview-indian healing-traditions.

Ningappa, M.B. and Srinivas, L. (2008). Purification and characterization of approximately $35 \mathrm{kDa}$ antioxidant protein from curry leaves (Murraya koenigii L.). Toxicol. In vitro, 22:699-709.

Pan, S.; Litscher, G. and Gao, S. (2014). Historical perspective of traditional indigenous medical practices: The current renaissance and conservation of herbal resources. Evid. Based Complement. Altern. Med., pp:525340.

Pandey, M.M.; Rastogi, S. and Rawat, A.K.S. (2013). Indian traditional Ayurvedic system of medicine and nutritional supplementation. Evid. Based Complement Altern. Med., pp:376327.

Preuss, H.G.; Echard, B.; Polansky, M.M. and Anderson, R. (2006). Whole cinnamon and aqueous extracts ameliorate sucrose-induced blood pressure elevations in spontaneously hypertensive rats. J. Am. Coll. Nutr., 25:144-150.

Pushpangadan, P. (2013). Invited commentary: Ethnopharmacology and phytomedicine. Ann. Phytomed., 2(2):1-3.

Rana, K.K. and Rana, S. (2014). Review on present status and future of herbal medicine. Beats of Natural Sciences, 1(2):1-8.

Rani, M.P.; Krishna, M.S.; Padmakumari, K.P.; Raghu, K.G. and Sundaresan, A. (2012). Zingiber officinale extract exhibits antidiabetic potential via modulating glucose uptake, protein glycation and inhibiting adipocyte differentiation: An in vitro study. J. Sci. Food Agric., 92(9):1948-1955

Saraswat, M.; Reddy, P.Y.; Muthenna, P. and Reddy, G.B. (2009). Prevention of non-enzymic glycation of proteins by dietary agents: Prospects for alleviating diabetic complications. Br. J. Nutr., 101(11):1714-1721.

Saravanan, M.; Pandikumar, P.; Saravanan, S.; Toppo, E.; Pazhanivel, N. and Ignacimuthu, S. (2014). Lipolytic and antiadipogenic effects of $(3,3-$ dimethylallyl) halfordinol on 3T3-L1 adipocytes and high fat and fructose diet induced obese C57/BL6J mice. Eur. J. Pharmacol., 740:714-721.
Saxena, P.K.; Cole, I.B. and Murch, S.J. (2007). Approaches to quality plant based medicine: Significance of chemical profiling. In: Applications of Plant Metabolic Engineering, Verpoorte R, AlfermannAW, Johnson TS, eds. Dordrecht, the Netherlands: Springer, pp:311-330.

Shan, B.; Cai, Y. Z.; Sun, M. and Corke, H. (2005). Antioxidant capacity of 26 spice extracts and characterization of their phenolic constituents. J. Agric. Food Chem., 53:7749-7759.

Sharma, H.; Chandola, H.M.; Singh, G. and Basisht, G. (2007). Utilization of Ayurveda in health care: An approach for prevention, health promotion, and treatment of disease. Part 1-Ayurveda, the science of life. J. Altern. Complement. Med., 13(9):1011-1019.

Sheth, P.P. (2005). Global opportunities and challenges for medicinal uses of Ayurveda, herbal products, nutraceuticals and alternatives. Health Administrator, 19(1):74-75.

Status of Indian medicine and folk healing: With a focus on integration of AYUSH medical systems in healthcare delivery. Ayush, 2012; 33(4):461-465.

Solomon, T.P. and Blannin, A.K. (2009). Changes in glucose tolerance and insulin sensitivity following 2 weeks of daily cinnamon ingestion in healthy humans. Eur. J. Appl. Physiol., 105:969-976.

Sowbhagya, H.B. (2013). Chemistry, technology, and nutraceutical functions of cumin (Cuminum cyminum L): An overview. Crit. Rev. Food Sci. Nutr., 53(1):1-10.

Subramoniam, A. (2014). Phytomedicine for healthcare. Ann. Phytomed., 3(1):1-3.

Suliman, S.; Elmahdi, B. and Abuelgasim, A. (2008). The effect of feeding Coriandrum sativum fruits powder on the plasma lipids profile in cholesterol-fed rats. Res. J. Ani. Vet. Sci., 3:24-28.

Villatgamuwa, S.A.; Platel, K.; Saraswathi, G. and Srinivasan, K. (1998). Antidiabetic influence of dietary cumin seeds (Cuminun cyminum) in streptozotocin induced diabetic rats. Nutr. Res. 18(1):131-142.

Wahab, A.; Ul Haq, R.; Ahmed, A.; Khan, R.A. and Raza, M. (2009). Anticonvulsant activities of nutmeg oil of Myristica fragrans. Phyto. Res., 23(2):153-158.

World Health Organization (2004). The World Medicines Situation.

World Health Organization (2013). Traditional Medicine Strategy, pp:20142023 .

Xie, J.T.; Chang, W.T.; Wang, C.Z; Mehendale, S.R.; Li, J.; Ambihaipahar, R.; Ambihaipahar, U.; Fong, H.H. and Yuan, C.S. (2006). Curry leaf(Murraya koenigii Spreng.) reduces blood cholesterol and glucose levels in ob/ob mice. Am. J. Chin. Med., 34:279-284.

Yadav, S.; Vats, V.; Dhunnoo, Y. and Grover, J.K. (2002). Hypoglycemic and antihyperglycemic activity of Murraya koenigii leaves in diabetic rats. J. Ethnopharmacol., 82:111-116. 


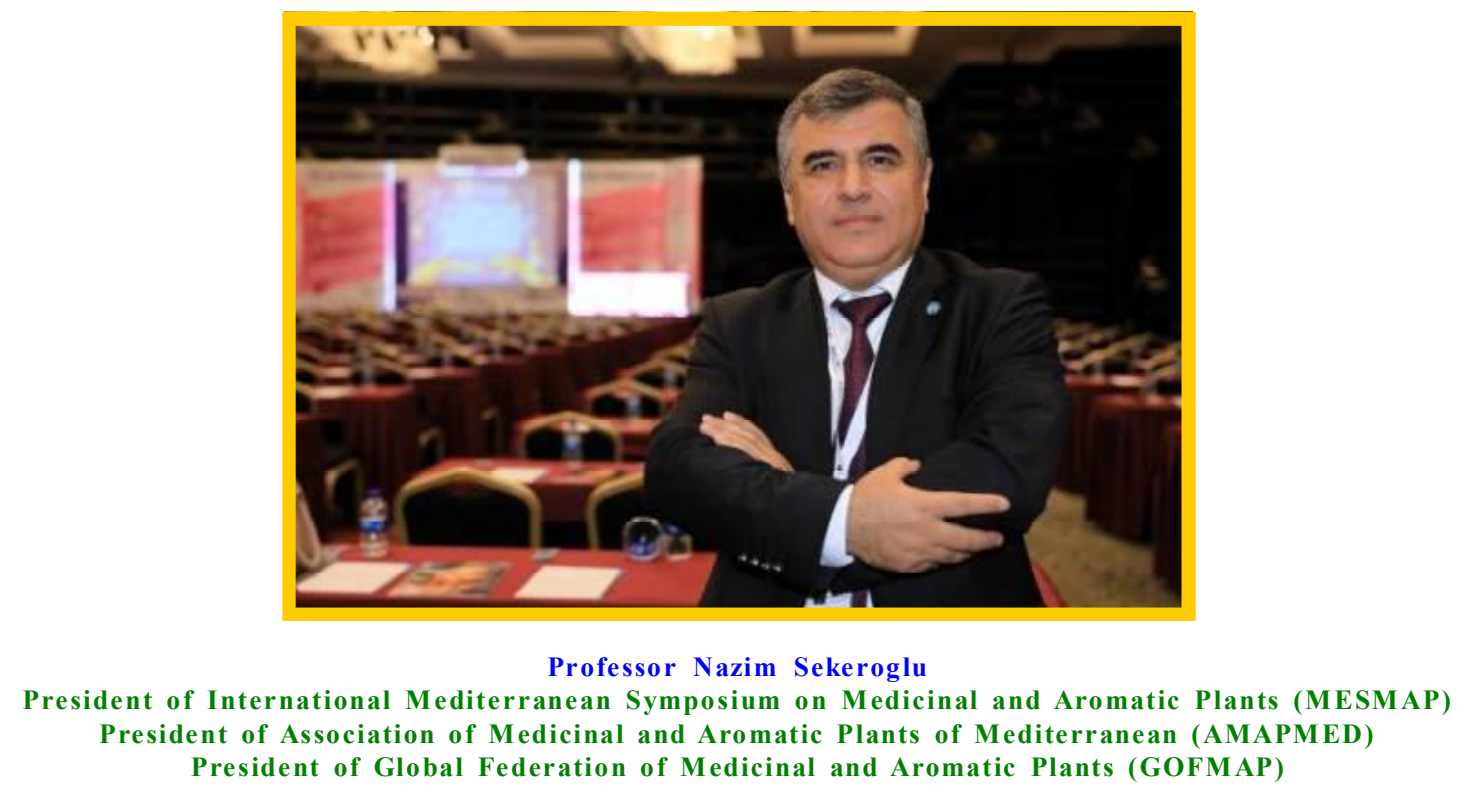

\section{Biography}

Professor Nazim Sekeroglu was born in 1972. He graduated from Field Crops Department, Agricultural Faculty, YuzuncuYil University in Van-Turkey. He got his PhD degree on agronomy and quality analysis of Medicinal and Aromatic Plants at Cukurova University, Adana-Turkey. Now, he has a 30 years' background of teaching and research activities in ethnobotany, wild edible plants, functional foods; cultivation, processing and analysis of medicinal and aromatic plants under the Fields Crops Department, at the Kilis 7 Aralýk University, Kilis-Turkey. He has many collaborations and research projects with agricultural and pharmacy faculties around the world. He has more than one hundred full text scientific papers at respected scientific journals and more than three hundred presentations as invited and plenary speaker, at scientific meetings on the worldwide. He was awarded by "Late Smt. Kamal Ben Vavia Memorial Award-2015" at "Pharmacy Institution of Madhya Paradesh, DAVV Auditorium, Takshash Campus, in Indore, India. Professor Sekeroglu is founder of some international associations related to Medicinal and Aromatic Plants like AMAPMED (Association of Medicinal and Aromatic Plants of Mediterranean), www.amapmed.org and GOFMAP (Global Federation of Medicinal and Aromatic Plants), www.gofmap.org. He is also a core committee member of AMAPSEEC (Association for Medicinal and Aromatic Plants of Southeast European Countries). As a founder and president of MESMAP (International Mediterranean Symposium on Medicinal and Aromatic Plants), www.mesmap.com scientific meetings, he has connected more than one thousands scientists studying on Medicinal and Aromatic Plants from all disciplines under the MESMAP umbrella throughout the world up to now. Presented scientific works at MESMAP symposiums have been published at special issues of respected journals, (e.g., Industrial Crops and Products by Elsevier; Annals of Phytomedicine: An International Journal by Ukaaz Publications, Hyderabad, India and Molecules by MDPI) with high impact factors. The sixth series of the well-known meeting, MESMAP-6 will be organized during April 16-19, 2020 in Ephesus, Izmir-Turkey. Professor Sekeroglu is the science director of the International Cosmetic Congress organized in Turkey, as well. He is editorial and advisory board member of many international scientific journals, symposiums and congress. $\mathrm{He}$ is also founder and Chief-editor of CUPMAP (Current Perspectives on Medicinal and Aromatic Plants), https:// dergipark.org.tr/en/pub/cupmap, an open access, peer-reviewed and refereed international journal published by MESMAP scientific group. He is member of scientific councils at the Turkish Ministries of Agriculture, Forestry and Industry. Besides his academic and scientific activities, he has also many administrative duties at university like manager, dean, vice rector and international relations coordinator. 